CRÍTICA, Revista Hispanoamericana de Filosofia

Vol. XXI, No. 61 (abril 1989): 43-73

\title{
ABSOLUTE TRUTH THEORIES FOR MODAL LANGUAGES AS THEORIES OF INTERPRETATION
}

ERNEST LEPore \& BarRy LOEWER Philosophy Department Rutgers University

Donald Davidson [1973a, 1977], Gilbert Harman [1972], and, in particular, John Wallace [1972, 1975], have identified some difficulties in constructing absolute truth theories for languages containing intensional operators. Wallace argues that the standard recursion clause for negation, (1), has no analogue for "necessity", and a range of other intensional operators. (2), for example, is false:

1. "It is not the case that $p$ " is true iff it is not the case that "p" is true.

2. "It is necessary that $\mathrm{p}$ " is true iff it is necessary that "p" is true.

"It is necessary that triangles are three sided" can be true, even though it is not necessary that "Triangles are three sided" is true. The quotation might have meant something different than the proposition that triangles are three sided.

Anil Gupta [1978] and Christopher Peacocke [1978] respond to Wallace by devising truth theories which, though containing clauses similar to (2), are not false. [See also Bladwin 1975, 1978, McGinn 1980, Thomason 1976.] In this paper, we argue that, though Cupta and 
Peacocke circumvent Wallace's objection, there is a cost: the truth theories they propose cannot function as theories of interpretation for any language. Since we have argued that the firmest grip we have on theories of interpretation are supplied by truth theories, this cost is too high [LePore 1982a, 1983, Loewer 1982, LePore and Loewer $1981,1983,1985,1988]$. We then consider possible world semantics (hereafter, PWS) for modal languages. It is widely thought that PWS can provide truth theories for modal languages [e. g., Hintikka 1969], but we will argue that PWS cannot be converted into truth theories suitable for interpretation. Lastly, we sketch an adequate semantic account for modal languages, qua theories of interpretation, by viewing modalities as predicates, much as Davidson proposes we view propositional attitude ascriptions as predicative. We begin by discussing what we mean by a theory of interpretation and in what way a truth theory for a language $\mathrm{L}$ can, under conditions we elucidate, be part of a theory of interpretation for L. Our account, though based on Davidson's, has its own twist.

Davidson's view is that a theory of interpretation for $\mathrm{L}$ should provide a statement $\mathrm{T}$, where if someone knows that $T$, he understands $\mathrm{L}$. His solution for $\mathrm{T}$ is a truth theory for $\mathrm{L}$, which issues in ascriptions of truth conditions for each (indicative) sentence of L. Why should we think this knowledge sufficient for understanding $L$ ? $^{1}$ Someone who understands L, and someone who does not, can still both hear utterances in $\mathrm{L}$ as productions of sounds. But someone who understands $\mathrm{L}$ will be warranted in reading sense into these sounds in way which someone who does not understand L will not. Suppose Art looks at the window; Bob and Carl are in the same room with Art, but cannot see out the window. Art and

1 The following is a sketch of the view we develop and defend in our papers referenced above. 
Bob, but not Carl, understand German. Art assertively utters "Es schneit". Since Bob understands German, he knows that Art asserted that it is snowing. If Bob believes Art is both confident (sincere) and competent (reliable), he may be warranted in believing Art believes that it is snowing and that it is snowing. ${ }^{2}$ Carl, however, at best, is warranted in believing Art asserted something or assertively uttered the sentence "Es schneit". Learning of Art's veracity, Carl may be warranted in believing, despite his ignorance of German, that Art said something true. What more need Carl know to be warranted in believing that it is snowing, on the basis of Art's utterance? An answer is that if he knew (3); he would be in a position to put two and two together, and so, be warranted in believing that it is snowing:

3. "Es schneit" is true, on that occasion iff it is snowing.

A theory of interpretation for a language $\mathrm{L}$ is a theory which warrants someone who knows it in those beliefs which a normal speaker of $L$ is warranted in believing on the basis of understanding $\mathrm{L}^{3}$

An interpretation theory must meet some conditions, if it is empirically adequate. For any $\mathrm{T}$, it must be possible to know that $\mathrm{T}$, without, thereby, knowing $\mathrm{T}$ is correct. This requirement is not idiosyncratic of interpretation; it holds for any adequate empirical theory. It should be possible to understand a theory of physics without, thereby,

2 This assumes Bob has no overridding beliefs. For example, he does not believe that an artificial snow maker is producing what Art sees.

3 This need not mean that understanding a language consists in knowing a truth theory for sentences of one's language. It may be that understanding a language does not consist in having knowledge, or beliefs, at all, but is a skill of some sort. But, even if explicit, or implicit, knowledge of a truth theory is not involved in Bob's understanding Art's utterances, it is true that if Carl knew a truth theory which issued in (3), he would be warranted in interpreting the utterance. 
knowing the explanations of the various physical phenomena which fall under its scope are correct. Assuming a theory adequate for its task, understanding of the theory alone should not provide knowledge of its intented domain. The following truth theory, qua empirical theory of interpretation, is excluded by this condition:

\section{4. (S) ("S" is true iff $S$ ),}

where the quantifier is substitutional and suitable precautions are taken to permit quantification into quotation. ${ }^{4}$ (4) must be stated in the language of the theory, in this case, English; otherwise, the substitutional quantifier in it is non-sensical. Witness the non-sensical result when the substituends are from German:

5. "Es schneit" is true iff es schneit.

The substituends for the quantifier in (4) must be English sentences. But, therefore, to understand (4) you must recognize its substituends as English. Thus, (4) violates the first condition.

There is a second condition which will figure deeply in our discussion of Peacocke's and Gupta's truth theories. We previously observed that a theory of. interpretation for German warrants Carl's belief, all things being equal, that it is snowing, when he hears "Es schneit". Of course, knowledge of the theory alone does not entail that he believes it is snowing. Carl needs to believe Art's utterance is true. This knowledge he does not acquire from the theory, but rather is based on independent evidence he has about Art's veracity. If it were not possible for Carl to recognize an utterance as true, without understanding it, then a truth theory, qua theory of interpretation, would be superfluous: entertaining the truth of an utterance

For elucidation of this theory, and an elaboration of the criticism, see LePore and Loewer 1983. 
alone would already require understanding it. Why is this bad? Because a truth theory has consequences of the form:

\section{Con $\mathrm{T}: \mathrm{S}$ is true iff $\mathrm{p}$.}

It is instances of Con $\mathrm{T}$ which should enable their knower to interpret sentences. But, then, it should be possible to recognize a sentence $S$ is true without understanding it. Insofar as S's being true forces its interpretation, the truth theory from which it issues is superfluous for interpreting the language of which $\mathrm{S}$ is a sentence. This is Davidson's point when he insists that the evidence which tests a theory of interpretation

must also be evidence we can imagine the virgin investigator having without his already being in possession of the theory it is supposed to be evidence for [1974a: 148].

The description of the evidence should be neutral. It should not by itself entail interpretations of sentences for $\mathrm{L}$. This is the job of the theory of interpretation.

Since Davidson argues that the evidence for a truth theory will take the form of utterances held true by speakers of the language under investigation [Davidson $1973 \mathrm{~b}]$, and since he argues separately that sentences held true by a community are true [Davidson 1974b, 1977], he holds that knowledge of the truth of a sentence ought not to entail knowledge of the proposition it expresses; otherwise, we would have the virgin investigator interpreting sentences in virtue of his having access to the evidence for his theory alone, without "possession of the theory [the evidence] is supposed to be evidence for". Nothing is idiosyncratic about this condition. It is a constraint any adequate theory should satisfy. A description of the evidence should not entail knowledge of the theory's intended domain. If it does, the theory's 
contribution to any account of this intended domain is superfluous.

What form can a truth theory, as a theory of interpretation, take for a language containing a class of grammatical modifiers which function syntactically as sentence modifiers, for example, "It is necessary that", "John believes that", "It is possible that", "Michael desires that"? These constructions are productive in English. We can place any indicative sentences from English after each construction salva well-formedness. How, though, within a truth theory for English are we to accommodate this potential infinitude of sentences, each of these constructions introduces into English?

In classical Tarskian truth theories, the recursion clauses for conjunction and negation use "and" and "not" respectively, and so on, for other productive constructions. It is, therefore, natural to think "It is necessary that" can be used in a standard recursion clause for necessitation. If the sentence mentioned on the left uses "It is necessary that", then the sentence on the right uses this phrase. In fact, Tarski himself appears to expect every meaningful expression of the object language to have a translation in the metalanguage [1956]. So, we set out to construct a Tarskian truth theory for English in which modal expressions mentioned in the object language, appear in the metalanguage as used non-extensional unary operators:

2. "It is necessary that $p$ " is true iff it is necessary that " $\mathrm{p}$ " is true.

Unfortunately, it is not so easy. (2), since it introduces a modal operator into the metalanguage, raises the question, what warrants substitutions within the scope of such operators in the metalanguage? The natural answer is to strengthen the axioms of the truth theory such that 
it is provable, for any sentence $\mathrm{p}$ of the object language, the appropiate instance of Con $\mathrm{T}$.

Let $L$ consist of two atomic sentences "It is snowing" and "It is raining" and any sentence generable from these by ordinary conjunction, negation, and necessitation. A truth theory for L, if it contains (2), also must contain the following necessitations:

7. It is necessary that ("S and $Q$ " is true iff " $S$ " is true and " $Q$ " is true)

8. It is necessary that ("It is not the case that $S^{n}$ is true iff it is not the case that " $\mathrm{S}^{n}$ is true)

9. It is necessary that ("It is snowing" is true iff it is snowing)

10. It is necessary that ("It is raining" is true iff it is raining)

These axioms license replacing the left hand side with the right hand side in all contexts. With them (and (2)), all instances of Con $\mathrm{T}$ are derivable, provided the logic of the metalanguage is as strong as $\mathrm{S}_{4}$, that is, provided the logic of the metalanguage has the axiom:

"It is necessary that p" $\rightarrow$ "It is necessary that it is necessary that $\mathrm{p}$ ",

where " $\mathrm{p}$ " is replaced by non-modal sentence of the object language. Without this axiom, Con $\mathrm{T}$ cannot be satisfied for every modal sentence of the object language [Gupta 1978: 118-19]. We turn to Wallace's objections and Gupta's and Peacocke's efforts to circumvent them.

Both Wallace [1975: 59] and Harman [1972: 300] criticize theories of the above sort because, for most interpretations of necessity, they argue (7)-(10) are false. It is not logical, metaphysical, or physical, necessity that "It is snowing" is true iff it is snowing. They conclude that "It is necessary that" cannot be treated as a unary 
operator on sentences in the metalanguage, since this move forced (7)-(10). [Underlying this objection is a fundamental requirement on a truth theory, as a theory of interpretation, namely, that it be true. This condition is trivial. Any theory not potentially true is unknowable.] Gupta and Peacocke reply to Wallace's argument in similar ways. Before reviewing their replies, though, we will review the special context in which they arise.

Each is concerned to defend the importance of modal logics against certain criticisms. In particular, they interpret Wallace as attempting to show modal languages are not suitable for the formulation of theories, cum theories of interpretation. If successful, Wallace argument would show that object language sentences like "It is necessary that it is raining" are only superficially of the form: Operator + Sentence. The genuine logical form of "It is necessary that $S$ " is a logical quantification. If correct, this would show that "modal logic" is only a surface logic, providing only ersatz logical forms.

Peacocke constructs truth theories which contain the truth predicate "is true in $\mathrm{L}^{*}$ ", where " $\mathrm{L}$ " is a rigid designator which designates a particular language. He claims that if an expression has a certain meaning in $\mathrm{L}^{*}$, then it must have that meaning in $L^{*}$ :

Expressions could not have meant anything else in that very language $L^{*}$. [ " $L$ "" is a proper name of that language.] Languages here are identified by the meanings of the expression in them, and languages in which "-" meant something other than negation would not be $L^{*}$ [1978: 477-478].

This assumption about individuating languages implies (11) and (12):

11. "It is necessary that $p$ " is true in $L^{*}$ iff it is necessary that " $p$ " is true in $L^{*}$.

12. It is necessary that ( $p$ " is true in $L^{*}$ iff $p$ ). 
Elsewhere, Peacocke says that the meanings theories of meaning (or truth theories) assign to sentences necessarily hold of those sentences, since these theories are for possible languages [1976]. However, a theory of interpretation can still make empirical claims, because its role is to determine of some particular population that it speaks the language in question. And, this is an empirical claim.

Gupta too constructs a homophonic truth theory for a modal language $\mathrm{L}$ in a modal metalanguage. Wallace objected that homophonic ["homomorphic" would be better] truth theories contain false clauses, since it is not necessary that symbols have the interpretations they in fact have. "It is raining" might have meant something quite different, for example, that it is snowing. If "It is necessary that" means the same thing as, or something like, "in all possible worlds it is true that", then (9) and (10), for example, are false. Gupta agrees. He suggests that the difficulty lies in the truth predicate employed in these sentences. His strategy is to introduce two concepts of truth: $\mathrm{T}_{1}$ and $\mathrm{T}_{2}$. He characterizes them as follows:

On the first concept [here represented by $T_{1}$ ], a sentence $A$ is true in a world $w$ if, and only if, $A$ is true with the meaning it has (in L) in w. On the second concept of truth (here represented as $T_{2}$ ] a sentence $A$ is true in $w$ if, and only if, $A$ is true in $w$ with the meaning it has in the actual world [1978: 120-121].

He proffers the following as an equivalent characterization, in terms of propositional truth:

A belongs to the extension of $T_{1}$ at $w$ if, and only if, there is a proposition $p$ such that $A$ expresses (in $L$ ) $p$ in $w$ and $p$ is true in $w$. A belongs to the extension of $T_{2}$ at $w$ if, and only if, there is a proposition $\mathrm{p}$ such that $\mathrm{A}$ expresses $\mathrm{p}$ in the actual world and $p$ is true in $w$ [1978: 121].

Gupta observes that, although (13) and (14) are false, both (14) and (15) are true: 
13. "It is necessary that $p$ " is $T_{1}$ iff it is necessary that "p" is $T_{1}$.

14. It is necessary that (" $p$ " is $T_{1}$ iff $p$ ).

15. "It is necessary that $p$ " is $T_{2}$ iff it is necessary that "p" is $\mathrm{T}_{2}$.

16. It is necessary that (" $p$ " is $T_{2}$ iff $p$ ).

Wallace's objection applies to $T_{1}$, but not to $T_{2}$. If "It is necessary that $p$ " is $T_{2}$, then it is necessary that " $p$ " is $T_{2}$, since, in determining whether it is necessary that " $p$ " is $\mathrm{T}_{2}$, only worlds at which " $\mathrm{p}$ " expresses the proposition it expresses in the actual world are relevant. Gupta's solution is to formulate a homophonic truth theory employing $T_{2}$ in place of $T_{1}$. He further observes that if one adds (17) to the homophonic theory employing $\mathrm{T}_{2}$, instances of Con $\mathrm{T}$ employing $\mathrm{T}_{1}$ are derivable as well:

\section{7. ( $\mathrm{S})\left(\mathrm{S}\right.$ is $\mathrm{T}_{2}$ iff $\mathrm{S}$ is $\mathrm{T}_{1}$ ).}

Furthermore, (17), while not necessarily true, is contingently true, since it is evaluated at the actual world $\$$, and therefore, since $\mathrm{w}=\$$, for the purposes of evaluating (17), $\mathrm{T}_{1}$ and $\mathrm{T}_{2}$ are extensionally equivalent (at $\left.\$\right){ }^{5}$

Peacocke's and Gupta's proposals work for the same reason, and come, pretty much, to the same thing. They work by using a truth predicate which applies to a sentence at a world $w$ iff the sentence is true at $w$, with the meaning it expresses at the actual world $\$$. It is irrelevant if the sentence expresses some other proposition at w. Wallace's objection involves supposing that "It is necessary that p" can be true, even though "It is necessary that ' $p$ ' is true" is false, since " $p$ " might express some proposition other than the one it actually expresses. By using the truth predicates "is $\mathrm{T}_{2}$ " and "is true at $\mathrm{L}^{*}$ ", instead of "is $\mathrm{T}_{1}$ ", this objection is avoided. That the

5 See, also, Thomason 1976, especially, 132. 
two proposals are equivalent can be seen by noting that (18) is true:

\section{It is necessary that ( $S$ is $T_{2}$ iff $S$ is $T_{1}$ in $L^{*}$ )}

We now argue that, though Peacocke's and Gupta's truth theories avoid Wallace's objection, they do not meet adequacy conditions on interpretation theories. First, two observations which apply to both accounts: neither generalizes for languages whose logics are weaker than $S_{4}$, because the logic of the object language must be $\mathrm{S}_{4}$, if the logic of the metalanguage is $\mathrm{S}_{4}$. And, on both accounts, the logic of the metalanguage must be at least as strong as $\mathrm{S}_{4}$; otherwise, it will not support substitutions necessary for deriving $\mathrm{T}$-sentences. Also, neither account generalizes to counterfactuals, or to propositional attitudes; it is false that if someone believes that $p$, then she believes that she believes that $\mathrm{p}$, an instantiation of the $\mathrm{S}_{4}$ axiom. And, for most propositional attitudes, sentences like (9) and (10) are false. "John believes that it is raining' is $\mathrm{T}_{2}$ iff John believes that 'It is raining' is $\mathrm{T}_{2}$ " is false, because the left hand side may be true, even though John knows not a single word of English, but the right hand side, though not requiring John understands English, requires he has beliefs about English. Adding $T_{1}$, instead of $T_{2}$, does not remedy this problem. Similarly, the clause for counterfactuals would be: "A > $B$ " is $T_{2}$ if, and only if, " $A$ " is $T_{2}>$ " $B$ " is $T_{2}$. The right hand side might be true, while the left hand side false, if the closest possible world in which " $A$ " is $T_{2}$ are worlds at which " $B$ " is true, but " $B$ " is not $T_{2}$, because " $B$ " expresses a proposition other than the proposition it expresses at the actual world.

We have no quarrel with either Gupta's or Peacocke's claim that there are true homophonic truth theories for modal languages employing either $T_{2}$ or $T_{1}$ in $L^{*}$. Both 
authors have shown how to construct truth theories for modal languages in such a way that "It is necessary that S is true iff p" is not false. Therefore, these authors overcome Wallace's objection, but they do so at a cost: theories which employ " $\mathrm{T}_{2}$ " or " $\mathrm{T}_{1}$ at $\mathrm{L}^{*}$ " cannot be employed as empirical interpretation theories. If our argument is sound, it undermines Gupta's position inasmuch as he accepts the claim that if a homophonic truth theory suitable to be an empirical interpretation theory cannot be constructed, then modal logic does not provide genuine logical forms [1978: 113, 115].

Use of $\mathrm{T}_{2}$ in the paradigm of interpretation results in:

19. Bob knows that Art's utterance "Es schneit" is $\mathrm{T}_{2}$.

20. Bob knows that "Es schneit" is $T_{2}$ iff it is snowing.

Therefore, Bob knows that it is snowing.

It should be possible for Bob to have the knowledge expressed by (19), without understanding the meaning of "Es schneit". This is required, since (20) is intented to isolate the knowledge his understanding consists in. It is precisely this requirement which is violated when $T_{2}$ is employed. (19) already ascribes to Bob an understanding of the truth conditions for "Es schneit". This can be seen by noting that to know that "Es schneit" is $T_{2}$ is to know that - to paraphrase Gupta- "Es schneit" is true with the meaning it has in the actual world. But it is impossible to know this without knowing what that meaning, that is, truth conditions, is. If this were not so, there would be no difference between knowing "Es schneit" is $T_{2}$, and knowing it is $T_{1}$. The difference, we claim, is that the former requires knowing the interpretation of "Es schneit" as well as knowing it is true under that interpretation. 
It is easy to miss this point, since it is easy to confuse (19) with $\left(19^{\prime}\right)$ :

19'. Bob knows that "Es schneit' is $\mathrm{T}_{2}$ " is true, where "is true" expresses the first concept of truth. Of course, it is possible for Bob to have this knowledge, without understanding "Es schneit", for reasons like those we gave in arguing that he could know "Es schneit" is true without understanding "Es schneit". But (19) ascribes to Bob not merely knowledge that a certain sequence of words is true, but also knowledge of the actual interpretation of those words.

We can make this point slightly differently if we employ Gupta's possible world account of these two concepts, with a possible world truth conditions account for knowledge statements. "Bob knows that $S$ is $T_{1}$ " is true iff Bob knows that (E!p) (S expresses $p$, and $p$ ). This holds just in case in each possible world, w, compatible with what Bob knows, $S$ expresses a proposition $\mathrm{p}$ in $\mathrm{w}$, and $\mathrm{p}$-in-w. On this formulation, $\mathrm{S}$ may express different propositions in various worlds compatible with what Bob knows. Bob knows that whatever proposition $S$ expresses, it is true. In contrast, "Bob knows that $\mathrm{S}$ is $\mathrm{T}_{2}$ " is true iff Bob knows that the proposition actually expressed by $\mathrm{S}$ is true. This ascribes to Bob de re knowledge. [That this knowledge is de re is signaled by the word "actually". This word always takes wide scope. Small scope for it, that is, a de dicto reading, issues in $\mathrm{T}_{1}$.] It is de re in the sense that it is true iff $(E ! p)$ (Bob knows that $S$ expresses $\mathrm{p}$, and $\mathrm{p}$ ). But this requires that in all possible worlds, compatible with what Bob knows, $S$ expresses one and the same proposition, viz., the proposition actually expressed by $\mathrm{S}$. This is the same as saying that Bob knows which proposition is expressed by $\mathrm{S}$. Thus, to ascribe to someone knowledge that $\mathrm{S}$ is $\mathrm{T}_{2}$ is already to credit 
him with knowledge of the meaning of $\mathrm{S}$. This makes $\mathrm{T}_{2}$ ill-suited for interpretation.

Davidson's account of interpretation is more global than our own. He imagines an interpretor set in an alien culture. This radical interpretor, Davidson assumes, can recognize which sentences the natives "hold true", without himself understanding the native sentences. The notion of truth required for this enterprise is $T_{1}$, not $T_{2}$, since only someone who already understands $S$ can know it is $\mathrm{T}_{2}$. This conclusion may seem threatened by Gupta's observation that (17) is true. (In fact, it is analogous to "I am here now", which is analytic, though it expresses a contingent truth.]

17. (S) ( $\mathrm{S}$ is $\mathrm{T}_{2}$ iff $\mathrm{S}$ is $\mathrm{T}_{1}$.)

Gupta suggests that if we add (17) to a truth theory formulated in terms of $\mathrm{T}_{2}$, we obtain appropiate biconditionals containing $T_{1}$. While correct, this does not show that a truth theory formulated in terms of $\mathrm{T}_{2}$, augmented by (17), may serve as an interpretation theory. An attempt to make it so serve is:

21. Bob knows that "Es schneit" is $T_{1}$.

22. Bob knows that "Es schneit" is $T_{1}$ iff "Es schneit" is $T_{2}$.

23. Bob knows that "Es schneit" is $T_{2}$.

24. Bob knows that "Es schneit" is $\mathrm{T}_{2}$ iff it is snowing.

Therefore, Bob knows that it is snowing.

This inference seems valid, and indeed, comments Gupta makes suggest that this is what he has in mind [1978: 122]. Line (22) is justified by axiom (17). That the knowledge ascribed to Bob in (22) is far from innocuous is shown by the fact that it is used in deriving (23) from (21), and our previous discussion shows that (23) does, 
but (21) does not, ascribe to Bob knowledge of what "Es schneit" means. This suggests that (22) adds to Bob's knowledge that the proposition "Es schneit" expresses is true, the knowledge of which proposition "Es schneit" expresses. This suspicion is warranted.

" 'Es schneit' is $T_{1}$ iff 'Es schneit' is $T_{2}$ " says that whatever proposition "Es schneit" expresses, it is true iff the proposition actually expressed by "Es schneit" is true. It is impossible to know this without knowing which proposition "Es schneit" expresses. The correct formulation of (22), or at least a more perspicuous formulation of it, is:

(E!p) ("Es schneit" expresses that p, and Bob knows that ("Es schneit" expresses that $p$, and $p$ iff (E!q) ("Es schneit" expresses that q, and q)))

The reason that (17), and its instances, appear innocuous is that they are undoubtedly true. But it is possible to know that a certain sentence is true without knowing which proposition it expresses. One need not undertand English to know that "Es schneit' is $T_{1}$ iff 'Es schneit' is $\mathrm{T}_{2}$ " is true, but only someone who knows a bit of English could know what is expressed by this quotation. Knowledge of what (17) expresses is not at all trivial; it is precisely the knowledge of the meanings of sentences of L. If we were to assume Bob had this knowledge, there would be no work for the theory of interpretation to perform. It is this knowledge the theory of interpretation is supposed to express. ${ }^{6}$

Peacocke's proposal suggests what appears initially to be an alternative to Gupta's strategy for defusing Wallace's objection. His claim is that if the axioms of the theory explicitly include a proper name of the language,

- There may be a de dicto interpretation of (17), but not one which will support a move from (21) to (23). 
then they, and their consequences, are necessarily true. [Baldwin 1975 and McGinn 1980 make similar claims.] To Wallace's objection that the consequences of a truth theory are not necessary, since the expressions of $\mathrm{L}^{*}$ might have had different meanings from the ones they actually have, Peacocke suggests that languages be individuated in such a way that it is metaphysically impossible for the semantic properties of any expression of that language to change. So individuated, if " $\mathrm{L}$ " rigidly designates a language whose truth theory contains as an axiom:

25. "It is raining" is true if $L^{*}$ iff it is raining, then (26) is metaphysically necessary, and Wallace's objection is averted.

We might object that languages, at least, natural languages, are not individuated in the way Peacocke suggests. We do not count every change of meaning as a change of language. We mean something quite different when we say "If the Beatles had never existed, our language would not be the same", than when we say "If the Germans had won the war, our language would not be the same". But our objection to Peacocke's proposal is not this. It is that his truth theory cannot play the role of an empirical interpretation theory. That this is so is demonstrable by showing that "is true in $L^{*}$ " is equivalent to "is $\mathrm{T}_{2}$ ".

Suppose $L^{*}$ names an actual language, and the sentence $S$ of $L^{*}$ expresses the proposition that $p$. Then, on Peacocke's construal of "is true in $L^{*}$ ", " $S$ is true in $L^{*}$ " holds at a world $\mathrm{w}$ iff the proposition actually expressed by $S$, viz., that $p$, is true at $w$. Should the sentence $S$ express some other proposition at $\mathrm{w}$, it would not make a difference, since in that case, $S$ would not be a sentence of $L^{*}$ at w. [Presumably, $L^{*}$ would not exist at w.] " $S$ is 
$\mathrm{T}_{2}$ " holds at $\mathrm{w}$ iff the proposition actually expressed by $S$ is true at $w$, independently of which proposition $S$ may express at $w$. So, "S is true in $L^{*}$ ", and " $S$ is $T_{2}$ " express the same proposition. In fact, "(S) (it is necessary that ( $\mathrm{S}$ is true in $\mathrm{L}^{*}$ iff $\mathrm{S}$ is $\mathrm{T}_{2}$ ))" is a theorem of the theory which includes Gupta's and Peacocke's axioms.

We argued that knowledge of the proposition expressed by " $\mathrm{S}$ is $\mathrm{T}_{2}$ " already involves knowledge of the truth conditions of $\mathrm{S}$, and this rendered Gupta's theory untenable as an interpretation theory. Since " $\mathrm{S}$ is true in $\mathrm{L}^{*}$ " expresses the same proposition as " $\mathrm{S}$ is $\mathrm{T}_{2}$, that is, $\mathrm{T}_{2}=\mathrm{T}_{1}$ in $L^{*}$ ", Peacocke's theory is equally ineffectual as an interpretation theory. There is a more direct argument for this conclusion, motivated independently of our criticism of Gupta's account.

To understand Peacocke's theory, one must understand, assuming the theory is stated in English, sentences of the sort: "S is true in $\mathrm{L}^{*}$ iff $\mathrm{p}$ ", where " $\mathrm{L}$ " rigidly designates a language. Furthermore, one must understand the sentence in such a way that one recognizes that it expresses a necessary truth, and knows what necessary truth it expresses. What is involved in understanding a sentence containing a rigid designator? Kripke, when he introduced the notion, argued that it is possible to use a rigid designator to refer to its designation without having in mind any definite description, or sense, which picks out the designation [1972]. However, Kripke did not discuss what it is to understand a rigid designator. This question returns to haunt us when we consider exactly what knowledge is ascribed to someone when we say he believes that a is F, on the basis of his having asserted "a is F", with "a" rigid. The problem is: suppose when we say that Art knows that a is F, we ascribe to him knowledge that the proposition expressed by " $a$ is $F$ " is true. By Kripke's account, that proposition is the proposition 
that is true at a world just in case the individual $a$ is $\mathrm{F}$ at that world. Suppose "c" rigidly designates $a$. Then the proposition expressed by " $\mathrm{c}$ is $\mathrm{F}$ " is identical to the proposition expressed by " $\mathrm{a}$ is $\mathrm{F}$ ". On this view, it follows that if Art knows that a is $\mathrm{F}$, he also knows that $\mathrm{c}$ is $\mathrm{F}$. But examples, for example, "London", "Londres", show either proper names do not function as rigid designators in knowledge contexts, and/or the knowledge ascribed is not knowledge of the proposition expressed by " $\mathrm{a}$ is $\mathrm{F}$ ". It is something like the knowledge that the thing designated by " $\mathrm{a}$ " is $\mathrm{F}$, or knowledge that the $\mathrm{G}$ is $\mathrm{F}$, where "the $\mathrm{G}^{n}$ is some description. But, if this is so, then we can show that it cannot be an interpretor's knowledge that $S$ is true in the language designated by " $\mathrm{L}$ ", or knowledge that $S$ is true in the language satisfying "the G", which enables him to understand sentences from $L^{*}$.

Suppose what he knows, when he knows that $S$ is true in $L^{*}$, is that $S$ is true in the language designated by " $L$ ". Then, when he knows the theory, what he knows is that $\mathrm{S}$ is true in the language designated by " $\mathrm{L}$ " iff $\mathrm{p}$. But this is not knowledge of a necessary truth. So, Wallace's objection is applicable, because having a necessity operator range over this piece of propositional knowledge renders it false. The same is true for the description interpretation. The alternative is that when he knows that $S$ is true, he actually does know the proposition expressed by " $\mathrm{S}$ is true in $\mathrm{L}^{*}$ ". But what proposition is this? It is the proposition that is true at a world just in case $S$ means that $p$ at that world, and $S$ is true at that world. This means that the proposition expressed by "S is true in $L^{*}$ " implies that $S$ means that $p$, which runs contrary to our requirement that merely understanding a theory should not imply its truth, and that the statement of evidence for a theory, in this case, the sentences from 
the language under investigation are held true, should not imply its truth. ${ }^{7}$

Though Peacocke's and Gupta's homophonic theories cannot serve as empirical interpretation theories, we still must seek such theories for languages containing modal sentence fragments. No one denies we understand these fragments, and therefore, they fall within the scope of an interpretation of English. But what kind of divergence from homophony should we accept? PWS suggests itself. PWS makes use of a relative notion of truth at a world. The central axiom is:

26. "It is necessary that $S$ " is true iff for all worlds $\mathrm{w}, \mathrm{S}$ is true-in-w.

Truth theories with an axiom like (26) seem to support, in some way, Davidson's and Wallace's position that the logical form of necessity sentences is really an implicit quantification over possible worlds in much the same way that Russell's theory of descriptions and Davidson's theory of events are supposed to show that apparent logical form is not real logical form. This reduces interest in

7 Peacocke is sensitive to the idea that a truth theory should be able to serve as an empirical interpretation theory:

This position has the consequence that if the language parameter place of the semantic predicate used in a truth theory is filled by a proper name the axioms generally will each be either necessarily true or necessarily false. But it would be an error to conclude from this that our present defense of homophonic truth theories for languages containing "BOX" cannot be reconciled with Davidson's view of the truth theory as empirical theories of the languages of which they treat. For we can specify the languages by descriptions, the descriptions being given wide scope with respect to the modal operators of the axiom. Thus, where " $L$ " ranges over languages we might have such empirical axioms as:

(EL) $\left(\mathrm{L}^{\prime}\right)\left(\mathrm{L}^{\prime}\right.$ is spoken in community C iff ( $\left.\mathrm{L}^{\prime}=\mathrm{L}\right)$ \& BOX ( $\operatorname{Tr}$ ("BOX $A^{n}, L$ ) iff BOX TR (" $\left.\left.A^{\prime \prime}, L\right)\right)$ )

If we place this sentence within the scope of our ascriptions of knowledge (or belief) to Bob, we will be forced into giving our knowledge operator small scope (that is, de re knowledge, not de dicto), and that will be sufficient to refute Peacocke's claim that this description provides an empirical description of Bob's knowledge. 
modal logic as an interpretation theory, and appears to support Wallace's claim that interpreting a modal language involves reading quantification theory into the object language [Wallace 1975: 50$].^{8}$

This concern is not ours: we want to know whether PWS can be used to construct a truth theory for a language qua theory of interpretation for this language. Can a theory with clauses like (26) play a pivotal role in a theory of interpretation? Several objections have been raised against this proposal:

i. Many who dislike PWS accounts argue against them on metaphysical (ontological) grounds. Some have held that there is a problem in making sense of the locution "There is a possible world..." [Quine 1953].

ii. Others worry about PWS on epistemic grounds. Since we lack any causal, or spatio-temporal interrelations with possible worlds, other than our own, how can we have (particular) knowledge about these worlds [Richards 1975, Rescher 1975].

iii. Harman complains against this kind of proposal on the grounds that, contrary to Russell's and Davidson's proposals for descriptions and events respectively, there is no syntactic support for this divergence from homophony; there are no non-ad hoc transformations to convert "(w) (p-in-w)" back into "It is necessary that p" [1972: 302-303].

iv. Still, others challenge the intelligibility of the theorems PWS issues in. What does, for example, "red-in-a" mean?; which proposition does "p-in-the-actual-world" express? Also, there is the problem of iteration: what does "It is necessary that it

8 See, also, Harman 1972:

the form ascribed to the sentence in the object language named by what replaces " $x$ " is not being treated as semantically basic, since the form of the sentence replacing " $p$ " is being taken to be more basic [293].

what I find objectionable in these approaches is that the logical forms assigned to sentences of the object language are not taken seriously. They are not treated as semantically basic, since they are not used -only referred to- in giving truth conditions of sentences. Two different logical forms can be associated with an object language sentence, the form it officially is assigned by the theory, as well as the form of its translation in the metalanguage. There is unnecessary duplication [301]. 
is necessary that it's snowing' is true in a world w iff ( $\left.w^{\prime}\right)$ ('It's snowing' is true at $w$ at $\left.w^{\prime}\right)$ " mean? [Richards 1975, Haack 1977, Lycan 1979.]

$v$. Davidson himself has proffered an argument to show that extensional PWS for intensional fragments of English do not make for adequate interpretations of these fragments. First, he notes that, in these languages, there is a large gap in the expressive resources between the object language and the metalanguage. There are sentences in the metalanguage with the same "subject matter" as the object language sentences, but which cannot be translated into the object language, for example, " $\mathrm{a}$ is $\mathrm{F}$ in exactly two worlds". This makes the metalanguage essentially richer than the object language, and it therefore, violates one of Davidson's desiderata for interpretation theories, namely, that the conceptual machinery of the metalanguage not be too much richer than that of the object language. ${ }^{9}$

A realist about possible worlds might argue that the PWS itself gives meaning to sentences from the theory, contra (iv), that inasmuch as possible worlds have never led to paradox, or inconsistency, there is no good reason to find them metaphysically suspect, contra (i), that the causal theory of knowledge itself is bankrupt, and therefore, should not be employed as a measure for PWS, contra (ii), and finally, that transformational grammar is not sufficiently well-supported to be a measure for PWS, contra (iii).${ }^{10}$ However, regardless of whether PWS theorists would, or should, be moved by the above considerations, or by similar objections, appeal to PWS is insufficient for its knower to infer that it is necessary that $p$ from her knowledge that "It is necessary that p" is true.

Problems arise for the PWS account from employing a concept of relativized truth, truth relativized to a possible world. To see this, first see how, by employing PWS, we should support Bob's inference. Relativiza-

- See Hazen 1976 for a study of the expressive incompleteness of modal logics. See, also, Davidson $1973 a$.

10 Many of these counter-arguments can be found in Lewis 1973. 
tion to worlds in (26) requires relativization to worlds in each clause in the truth theory, for reason similar to the required necessitations of the base axioms in Gupta's and Peacocke's proposals. Without such relativizations, we could not make the substitutions needed for deriving each instance of Con ' $\mathrm{T}$. Using PWS, with the needed relativizations, results is:

27. Bob knows that $S$ is true-in- $\$$, where "\$" refers to the actual world.

28. Bob knows that ( $w$ ) ( $\mathrm{S}$ is true in $w$ iff $p$-in-w).

29 . Bob knows that $S$ is true-in- $\$$ iff $p$-in- $\$$.

30. Bob knows that p-in-\$.

Bob begins by knowing $S$ is true, and is supposed to end by knowing that $\mathrm{p}$. What knowledge would license this move from (31) to (29), and from (30) to (32)?

31. $\mathrm{S}$ is true.

32. $\mathrm{p}$

The first instance would be supported by the generalization:

33. ( $\mathrm{S}$ ) ( $\mathrm{S}$ is true iff $\mathrm{S}$ is true-in- $\$$ )

This, perhaps, is harmless enough, but severe problems arise in moving from (30) to (32). Warranting this move requires some statement of which an interpretor's knowledge would license the inference from $\mathrm{p}$-in- $\$$ (or $\mathrm{p}$-in-w), to $p$, for each $p$ in the language. It may seem that the following works:

24. (p) (p iff $p$-in- $\$$ )

But this is incoherent. The two occurrences of $p$ are semantically quite distinct. The first is a sentence, and the second is a predicate of possible worlds. It makes no sense to bind them with one quantifier. That $p$ occurs 
in "p-in-\$" and in "p-in-w" is, at least under the available apparatus, an orthographic accident. The proposition that $p$ will be either contingently true, or false, but $p$-in- $\$$ is either necessarily true or false. Therefore, we have no reason to believe that that $p$ is in anyway connected to p-in- $\$$. What we need are infinitely many instances of (34), with no obvious way available. ${ }^{11}$

At least one author holds there is no difficulty involved in assuming (34). Harman writes:

It is a mistake to think that possible worlds are relevant on the ground that knowing the meaning of a sentence is knowing which possible worlds the sentence is true in. Perhaps, knowing the meaning of "Snow is white" involves knowing that this sentence is true in a, world if, and only if, snow is white in that world, but the appeal to possible worlds is superfluous. One can just as well say that knowing the meaning of the sentence involves knowing it is true if, and only if, snow is white, without mentioning possible worlds at all [1972: 306].

Though propositions that $\mathrm{p}$, and that $\mathrm{p}$-in- $\$$, are different, they agree in truth value (at $\$$, the actual world). If it is true that $\mathrm{p}$, then it is true that $\mathrm{p}$-in-\$, and vice versa. Therefore, $\mathrm{p}$ is true iff $\mathrm{p}$-in- $\$$ is true, and we can exploit this equivalence in deriving individual inferences from sentences held true to an appropriate non-linguistic belief that p. And, apparently, we can then complete the chain of reasoning we have been probing. However, if this is Harman's point when he writes that reference to possible worlds is superfluous, he is mistaken.

Suppose Bob is in a world b $(=/=\$)$. A reliable German speaker utters to him "Es schneit", from which Bob is licensed to infer, by (33), that:

35. "Es schneit" is true-in-b.

11 See LePore 1983 for further discussion of the problems involved in using a relativized concept of truth in an interpretation theory. 
Since we assume (28), we can infer (36):

36. Bob knows that "Es schneit" is true-in-b iff it is snowing-in-b.

Therefore, Bob knows that:

37. It is snowing-in-b.

We can go no further. If the proposition it is snowing differs in truth value from the proposition that it is snowing-in- $b$, and there is no reason to assume that will not be so, then we lack anything like (33) to support inferences to the proposition that it's snowing. This suggests that PWS, when it works, does so only because of the contingent equivalence (34); once we move to another world, unlike the actual world, the inferences no longer hold. Therefore, Harman is wrong that reference to "possible worlds is superfluous". The T-sentences he mentions are quite different, and will, contrary to what Harman believes, license very different inferences: ${ }^{12}$

"Es schneit" is true in a world iff it is snowing in that world.

"Es schneit" is true iff it is snowing.

So far we have been thwarted in our efforts to treat "It is necessary that" as functioning as a genuine semantic operator on sentences. Perhaps, we can view it

12 There is an interesting disanalogy here with tense. Consider the following sentences:

$(w)(S$ is true in $w$ iff $p$ in $w)$

$(t)$ ( $S$ is true at $t$ iff $p$ at $t)$

Since p-at-t is an eternal proposition, but $p$ need not be, there is no reason to believe that the propositions agree in truth value, and therefore, no reason to adopt the equivalence:

$p$ iff p-at-t, even where we let " $t$ " be an indexical, picking out now. Also, let " $p$ " stand for "It was in the past that", then the following operator treatment 
instead as predicative in character, in much the same way that Davidson proposes construing propositional attitude constructions as predicative: on his paratactic account, these sentence modifiers are parsed as two place predicates satisfied by a person and an utterance [Davidson 1968, 1969]. Davidson does so because of difficulties encountered by an operator treatment of psychological predicates. Consider:

"Galileo said that the earth is round" is true in L iff Galileo said that "The earth is round" is true in $\mathrm{L}$.

The left hand side of this equivalence may be true, but the right hand side is false. Galileo spoke no English, and most likely knew nothing about truth theories. Inasmuch as an operator treatment of psychological modifiers encounters difficulties analogous to the difficulties encountered in constructing an operator treatment of "It is necessary that", and also, inasmuch as there is a strong syntactic similarity between these constructions, an uniform semantic treatment suggests itself.

First, sentences like (38) are regimented into sentences like (39):

38. It is necessary that it is raining or not raining. 39. That is (logically) necessary. It is raining or not raining.

(An utterance of) the first sentence in (39) refers to (a subutterance of) the second, by the demostrative "that",

of "p" seems perfectly natural and acceptable:

"PS" is true iff P"S" is true.

There is the problem that $S$ may have had a different meaning than it does now, but this is not the same problem we are concerned with:

"Box $S$ " is true iff BOX " $\mathrm{S}$ " is true. 
and predicates of it (logical) necessity. ${ }^{13}$ On this account, the target $T$-sentence for (38) is not (40):

40. "It is necessary that it is raining or not raining" is true iff it is necessary that it is raining or not raining.

Under the present construal, the sentence "It is raining or not raining" is not a semantic component of (38), and therefore, it does not have its ordinary semantic role. Those substitutions ordinarily required for deriving a T-sentence for (38) do not preserve truth. The truth condition for (38) is not the same as that for (41):

41. It is necessary that it is not raining or it is raining.

(An utterance of) (38) demonstrates "It is raining or not raining", and therefore, substitutions leading to (41) are unjustified.

The truth of (an utterance of) a sentence like "That is (logically) necessary", with "that" taken as a demonstrative whose reference is fixed by pointing, as it were, in the direction of a certain item, could not entail the logical truth of a different sentence with the same truth conditions, with the reference of this other demonstrative, in (41), fixed by pointing at a different item.

What about the truth theory? Since, under the present proposal, our language contains indexicals, Davidson's recommendation that we modify. Tarski such that the truth predicate is characterized not as a one place predicate of sentences, but as a three place predicates of sentences, speakers, and times recommends itself: $\mathrm{A}$ is true,

13 See, LePore and Loewer 1989 for an elaboration and defense of the paratactic account in general. 
as potentially uttered by $\mathrm{B}$ at $\mathrm{t}$ [1967: $34-35] .{ }^{14}$ This predicate, then, can hold of a sentence, a person, and a time, even though the sentence is not then uttered by this person. With this modification, standard equivalences are derivable:

42. "It is necessary that" is true in English for a speaker, at a time, iff the demonstrated object by the speaker at this time is (logically) necessary.

This theory is formally feasible: we meet Con $\mathrm{T}$, and structural constraints are adequately respected. In addition, and more importantly, we have a proposal which provides an adequate solution to the puzzle about Bob:

43. Bob knows that "It is necessary that it is raining or not raining" is true.

44. Bob knows that the sentence "That is (logically) necessary" is true iff the demonstrated object [i. e., "It is raining or not raining"] is (logically) necessary. 45. Therefore, Bob knows that the demonstrated object is (logically) necessary.

Since "It is raining or not raining" is English, and since, by assumption, Bob already knows an adequate truth theory for English, minus its modal fragment, Bob knows that:

46. "It is raining or not raining" is true iff it is raining or not raining.

From this, we might be tempted to "complete" our line of reasoning to infer, from (45) and (46), that:

47. Bob knows that it is necessary that it is raining or not raining.

14 See, also, LePore and Loewer 1987,1989 for further elaboration of this account of indexicals. 
But, again, (47) does not follow, since "if, and only if" is extensional, and therefore, supports no such substitutions in opaque contexts like "It is necessary that". But this is no loss, for the point of the paratactic account is that the "true" logical form for sentences like (38) is (39), and in (39), the sentence in question does not appear. ${ }^{15}$

In conclusion, if the above argument is sound, then we have shown that, though Gupta and Peacocke avoid Wallace's objection, the cost of their tactics is to render their truth theories incapable of playing the role of an interpretation theory. Also, we have shown that knowledge of PWS, whether it is empirical or not, is insufficient for interpretation. And, lastly, we sketched a paratactic account for modal languages, which, of course, requires further elaboration. Prima facie, however, it seems to be on the right track.

15 Even though we seem to have devised an account for sentences using "It is necessary that" as a component, an account which seems both empirically adequate and which satisfies Con $\mathrm{T}$, we might wonder whether it is consistent. This question is pertinent, because of a result of Richard Montague's to the effect that necessity cannot be treated as a predicate in most modal logics, without inducing inconsistency [1960]. If Montague's result applies to the metalanguages of our proposal, then the truth theories we proffer would be illconsistent, and therefore, inadequate.

Montague's result requires that the logic of the metalanguage contain nothing stronger than $S_{1}$. But to construct a truth theory for an object language, the metalanguage need not satisfy Montague's requirements. All it need satisfy is that it have some restricted quantification for doing syntax and satisfaction clauses, and, in addition, the transitivity of the biconditional and a replacement schema, for the metalanguage as a whole [LePore $1982 \mathrm{~b}$ ]. With this little logic, Montague's result is not derivable in our truth theories, and therefore, we need not worry about inconsistency arising as a result of the predicative account for necessity. 


\section{BIBLIOGRAPHY}

Baldwin, Thomas, "Quantification, Modality, and Indirect Speech", Meaning, Reference, and Necessity, ed. Simon Blackburn, 1975.

_. "Kripke, Pseudo-Kripke, and Wallace", Analysis, 1978.

Davidson, Donald, (1967) "Truth and Meaning", Inquires into Truth and Interpretation, Oxford University Press, 1984: 17-36.

-, (1968) "On Saying That", op. cit.: 93-108.

-, (1969) "True to the Facts", op. cit.: 37-54.

- , (1973a) "In Defense of Convention T", op. cit.: 65-76.

-, (1973b) "Radical Interpretation", op. cit.: 125-140.

- $(1974 \mathrm{a})$ "Belief and the Basis of Meaning", op cit.: 141-154.

-, (1974b) "On the Very Idea of a Conceptual Scheme", op. cit.: $183-198$.

—, (1977) "The Method of Truth in Metaphysics", op. cit.: 119214.

Gupta, Anil, "Modal Logic and Truth", Journal of Philosophical Logic, volume 7, number 4, 1978: 451-472.

Haack, Susan, "Lewis' Ontological Slum", Review of Metaphysics, $33,1977$.

Harman, Gilbert, "Logical Form", Foundations of Language, 9, 1972: 289-307.

Hazen, A., Journal of Philosophy, 1976.

Hintikka, Jaakko, Modes for Modalities, Reidel, 1969.

Kripke, Saul, "Naming and Necessity", Semantics of Natural Language, D. Davidson, and G. Harman (eds.), Reidel, 1972: 253355.

LePore, Ernest, "In Defense of Davidson", Linguistics and Philosophy, 1982a: 277-294.

- - "Truth and Inference", Erkenntnis, 1982b: 379-395.

-, "What Model Theoretical Semantics Cannot Do", Synthese, 1983: $167-187$.

LePore, Ernest and Barry Loewer, "Translational Semantics", Synthese, 48, 1981: 121-133.

-, "Three Trivial Truth Theories", Canadian Journal of Philosophy, 1983: 433-447.

- - "Solipsistic Semantics", Midwest Studies in Philosophy, 1985: 595-614.

- ,Dual Aspect Semantics", New Direction in Semantics, Ernest LePore (ed.), Academic Press, 1987: 83-111.

- "You can Say That Again", Midwest Studies in Philosophy, 1989 , forthcoming. 
Lewis, David, Counterfactuals, Cambridge, Mass., Harvard University Press, 1973.

Loewer, Barry, "The Role of Conceptual Role Semantics", Notre Dame Journal of Formal Logic, 23, 1982.

Lycan, William, "The Trouble with Possible Worlds", The Possible and the Actual, M. Loux (ed.), Cornell University Press, 1979.

McGinn, Colin, "Operators, Predicates, and Truth-Theory", Reference, Truth, and Reality, Mark Platts (ed.), RKP, 1980: 199205.

Peacocke, Christopher, "Truth Definitions and Actual Languages", Truth and Meaning, G. Evans, and J. McDowell (eds.), Clarendon Press, Oxford, 1976: 162-187.

- "Necessity and Truth Theories", Journal of Philosophical Logic, volume 7, number 4, 1978: 473-500.

Quine, W. V. O., "On What There Is", From a Logical Point of View, Cambridge, Harvard University Press, 1953: 1-19.

Richards, T., "The Worlds of David Lewis", Australasian Journal of Philosophy, 53, 1975.

Rescher, N., A Theory of Possibility, 1975.

Tarski, Alfred, "The Concept of Truth in Formalized Languages", Logic, Semantics, and Metamathematics, Oxford, Clarendon Press, 1956: 182-365.

Thomason, Richmond, "Necessity, Quotation, and Truth: An Indexical Theory", Language in Focus, Asher Kasher (ed.), Reidel, 1976: 119-138.

Wallace, John, "On the Frame of Reference", Semantics of Natural Language, D. Davidson, and G. Harman (eds.), Reidel, 1972: 219-252.

- , "Non-Standard Theories of Truth", The Logic of Grammar, D. Davidson, and G. Harman (eds.), Dickenson, 1975: 50-59. 


\section{RESUMEN}

Donald Davidson, Gilbert Harman y, en particular, John Wallace han identificado en diferentes obras citadas en el texto algunas dificultades que se dan cuando se intenta construir teorias de verdad absoluta para lenguajes que contienen operadores intensionales. Wallace sostiene que la cláusula de recursión estándar para la negación, (1), no tiene una cláusula análoga para la "necesidad" y para toda una gama de operadores intensionales. (2), por ejemplo, es falsa:

1. "No es el caso que p" es verdadera sii no es el caso que "p" es verdadera.

2. "Es necesario que p" es verdadera sii es necesario que "p" es verdadera.

"Es necesario que los triángulos tengan tres lados" puede ser verdadera, aunque no es necesario que "los triángulos tienen tres lados" sea verdadera. La cita pudo haber significado algo distinto de lo que la proposición "los triángulos tienen tres lados" quiso decir.

Anil Gupta y Christopher Peacocke responden a Wallace diseñando teorias de verdad que, si bien contienen cláusulas similares a (2), no son falsas. En este artículo sostenemos que aunque Gupta y Peacocke hacen a un lado la objeción de Wallace, esto tiene un costo: las teorías de verdad que proponen no pueden funcionar como teorías de interpretación para ningún lenguaje. Puesto que hemos argumentado que las teorías de verdad son las que nos proporcionan la comprensión más sólida de las teorías de interpretación, este costo resulta demasiado elevado. Consideramos entonces una semántica de mundos posibles (SMP) para los lenguajes modales. Muchos piensan que la SMP puede ofrecer teorías de verdad para los lenguajes modales, pero veremos que la SMP no puede convertirse en una teoría de verdad que se preste para la interpretación. Por último, esbozamos una descripción semántica adecuada para los lenguajes modales qua teorías de interpretación, considerando las modalidades como predicados, de la misma forma como Davidson propone que concibamos las atribuciones de actitudes proposicionales como predicativas. Empezamos aclarando lo que queremos decir con "teoría de interpretación" y de qué manera una teoría de verdad para un lenguaje $L$ puede, bajo condiciones que dilucidamos, formar parte de una teoría de interpretación para L. Nuestra descripción, aunque se basa en la de Davidson, posee sus propias particularidades. 